\title{
Ocular Manifestation of Juvenile Idiopathic Arthritis and its Relation to Disease Activity
}

\author{
Rawhya R EL-Shereef ${ }^{1 *}$, Gehan lofty ${ }^{2}$, Ahmad Shawkat Mohamed ${ }^{3}$ and Lamiaa Hamdy ${ }^{4}$ \\ ${ }^{1}$ Assistant Professor of Rheumatology and Rehabilitation in El-Minia University Hospital, Egypt \\ ${ }^{2}$ Paediatric Department, El-Minia University Hospital, Egypt \\ ${ }^{3}$ Ophthalmology Department, El-Minia University Hospital, Egypt \\ ${ }^{4}$ Clinical Pathology Department, Faculty of Medicine, Al-Minia University
}

\begin{abstract}
Purpose:To determine the ocular manifestations of juvenile idiopathic arthritis (JIA) and its relation to its disease activity. To analyze the prevalence and complications of uveitis and their predictors in JIA.

Methods: Fifty eight JIA patients and 20 age and sex matched healthy controls were included in this study; all JIA patients were recruited from Rheumatology and paediatric department. All patients were undergone complete rheumatological and ophthalmic examination including visual acuity, slit lamp examination of the anterior segment, dry eye evaluation using Rose Bengal stain and Schirmer test. Fundus examination and fundus photography were done to the suspected cases

Results: Sixteen patients (27.6\%) had ocular manifestations. Most of JIA were asymptomatic 49 (84.48\%) for ocular manifestation. Nine patients (15.5\%) complained of ocular manifestations in the form of blurring of vision, burning sensation and eye dryness. Patients with ocular abnormalities had an earlier disease onset and longer disease duration than those without any lesions $(p<0.001)$. There was a highly statistically significant difference between patients and controls as regarding all ocular lesions, which was significantly higher in the patients group. Meanwhile, the most common ocular manifestation of JIA is uveitis $(17.2 \%)$, five patients had keratoconjunctivitis Sicca, 8 patients had visual field defects, also four had macular edema, two had cataract and two had increase intraocular pressure.
\end{abstract}

Conclusion: Ocular manifestations including sight threatening complications are not rare in patients with JIA Uveitis is the most common ocular lesion. Therefore, continuous ophthalmologic examinations are needed in young people with JIA.

Keywords: Juvenile idiopathic arthritis; Retina involvement; KCS; Dry eye; Uveitis

\section{Introduction}

Juvenile idiopathic arthritis is an autoimmune, non-infective, inflammatory joint disease of more than 3 months duration in children less than 16 years of age. The disease commonly occurs in children from the ages of 7 to 12 , but it may occur in adolescents as old as 15 years of age, as well as in infants [1]. It is a subset of arthritis seen in childhood, which may be transient and self-limited or chronic. It differs significantly from arthritis commonly seen in adults, and other types of arthritis that can present in childhood which are chronic conditions e.g. psoriatic arthritis and ankylosing spondylitis. Aetiopathology is similar to rheumatoid arthritis but with less marked cartilage erosion, joint instability and absent rheumatoid factor. JIA affects approximately 1 in 1,000 children in any given year, with about 1 in 10,000 having a more severe form [2]. JIA is the most common cause of uveitis in children and also major cause of visual impairment in children. The prevalence of uveitis in JIA patients varies from $4 \%$ to $38 \%$ [3,4]. JIA shows female preponderance with male female ratio of 2:3 and girls are five times more prone to have a longer course of the disease than boys. Chances of developing ocular manifestations are relatively more common in girls $[5,6]$. The most common extraarticular manifestation of JIA is intraocular inflammation. The intraocular inflammation seen in JIA patients is typically bilateral non granulomatous uveitis with chronic course [7]. However granulomatous uveitis with mutton-fat keratic precipitates (KPs) has also been reported [8]. Variable anterior chamber reaction with inflammatory cells in anterior vitreous can be seen in slit lamp examination. Posterior synechiae are common. Posterior segment involvement in JIA is usually rare though CME can occur. The common causes of visual impairment in JIA are complicated cataract and band shaped keratopathy (BSK). Secondary glaucoma is another vision robbing complication of JIA. Other complications associated with JIA are epiretinal membrane, macular hole, hypotony with ciliary body shutdown or atrophy [8].

\section{Subjects and Methods}

\section{Subjects}

The study included 58 JIA patients compared to 20 age and sex matched healthy controls. They were recruited from the Rheumatology and pediatric outpatient clinic of Minia University Hospital. The diagnosis of arthritis was made according to International League of Associations for Rheumatology (ILAR) classification and the diagnosis of uveitis was made according to the International Uveitis Study Group guidelines $[9,10]$. Each JIA patient underwent a complete history

*Corresponding author: Rawhya R EL-Shereef, El-Minia University Hospital, Egypt; E-mail: rawhyaelshereef@yahoo.com

Received May 09, 2014; Accepted July 17, 2014; Published July 25, 2014

Citation: EL-Shereef RR, lofty G, Mohamed AS, Hamdy L (2014) Ocular Manifestation of Juvenile Idiopathic Arthritis and its Relation to Disease Activity. $J$ Arthritis 3: 137. doi:10.4172/2167-7921.1000137

Copyright: $\odot 2014$ EL-Shereef RR, et al. This is an open-access article distributed under the terms of the Creative Commons Attribution License, which permits unrestricted use, distribution, and reproduction in any medium, provided the original author and source are credited. 
taking (including the symptoms of dryness of eye, blurring of vision, diminution of vision, itching and redness of eye). History of drugs was also included and their duration was recorded. Demographic and risk factor data were collected from both patients and controls. Full general, locomotor system and neurological examination were done to detect articular and extra-articular involvement and co-morbidities. Patients with systemic glucocorticoid treatment, topical ocular treatment and previous ocular laser or surgical treatment were excluded. We divided our subject into two groups, group 1 control, and group 11 JIA patients. According to the presence or absence of ocular lesions the JIA patients were subdivided into patients with ocular lesion (group 11a) and without ocular lesion (group 11b); the clinical and laboratory findings were compared between the subgroups. In JIA patients, disease activity was also assessed by a scale that quantifies the absolute level of disease activity, the Juvenile Arthritis Disease Activity Score (JADAS), which includes 4 items: (1) physician global assessment of disease activity, (2) parent/patient global assessment of wellbeing, (3) number of active joints, and (4) ESR [11]. Minimal disease activity (MDA), MDA [12]: (1) Oligoarthritis: physician global assessment $\leq 2.5 \mathrm{~cm}$ and swollen joint count of 0 (2) Polyarthritis: physician global assessment $\leq 3.4 \mathrm{~cm}$, parent global assessment $\leq 2.1 \mathrm{~cm}$, and swollen joint count $\leq 1$. Inactive isease/remission; Wallace criteria [13] In active disease: (1)No joints with active arthritis (2) No fever, rash, serositis, splenomegaly, or generalized lymphadenopathy attributable to JIA (3) No active uveitis, (4) Normal ESR and/or CRP (5) Physician global assessment indicates no disease activity Clinical remission:(1) On medication-criteria for inactive disease met for minimum 6 continuous months while patient on medication (2) Off medication-criteria for active disease met for minimum 12 continuous months while off all arthritis and uveitis medications.

\section{Methods}

All participants are subjected to the following investigations complete blood picture, the ESR was measured by the Westergren method, with a normal range of 0 to $20 \mathrm{~mm} / \mathrm{h}$. CRP was measured quantitatively by latex agglutination test (normal $0-6 \mathrm{mg} / \mathrm{l}$ ) The presence of rheumatoid factor in any of the immunoglobulin isotypes was considered positive, and ANA can be detected by indirect immunoflurescence assay. From these parameters, we can confirm the diagnosis of JIA and assess the degree of activity by JADAS.

One expert ophthalmologist carried out all the ophthalmological examinations without knowledge of the general condition of each patient or of laboratory findings for all patients and controls. The ophthalmological examination including visual acuity, visual field, slit lamp for examination of the anterior segment. To evaluate eye dryness, the following tests were done;

The first test was called Schirmer test in which strips were placed between the medial and the lateral part of the lower eyelids with use of local anaesthetic drops. After 5 minutes the strips were removed and the length of the wetted area of the strip was measured, arting from the notch corresponding to the inferior lid margin. The length less than 5 $\mathrm{mm}$ is pathological.

The second test was called Rose Bengal in which the staining was done using $1 \%$ rose Bengal solution which instilled in the conjunctival sac. After 30 seconds the sac is gently irrigated with saline solution and the eye is examined under magnification for red punctate staining of the cornea and conjunctiva.

Fundus examination was done to all patients but fundus photography was done to the suspected cases.
All of the available data from the rheumatological and ophthalmological database were analyzed. Data analysis was achieved with SPSS 11.0 statistical package under Windows 2007 (SPSS Advanced Statistics 11.0. Chicago SPSS Inc., IL, USA). The chi-square test for categorical data and Student's t-test were used for statistical analysis when appropriate. Logistic regression analyses were applied to identify predictors of uveitis and its complications at documentation. Results were expressed as odds ratios (ORs) and confidence intervals (CIs). A significance level of 5\% was used for all analyses

\section{Results}

\section{Characteristic of JIA patients}

Fifty eight (46 (79.3\%) females, 12 (20.7\%) males) patients of JIA fulfilled the International League of Associations for Rheumatology (ILAR) criteria for the classification of JIA. The mean age of the JIA patients was $10.2 \pm 3.2$ years, ranging from 6 to 19 years, while that of the controls was $9.80 \pm 6.46$ years ranging from $5-16 y$, the mean age at onset and disease duration of JIA patients was $6.9 \pm 2.2$ ranging from 4-13 years, and $38.5 \pm 32.8$ ranging from 6 to 116 months respectively (Table 1). As regard the drug taking, 34 patients $(58.6 \%)$ received antimalarial, 46 (79.3\%) received methotrexate, and 23 (39.7\%) received non steroidal anti-inflammatory drugs (NSAIDs), as single drug or combined (the most combined drug used is methotrexate, NSAIDs, and antimalarial). The majority of all JIA patients recorded had polyarthritis ( 27 patients), followed by oligoarthritis ( 20 patients) and then systemic onset (11 patients), uveitis was particularly common in patients with oligoarthritis. The JIA patients were subdivided into two groups according to presence or absence of ocular lesion, the first one was JIA patients with ocular lesions (group 11a) and the second group was JIA patients without ocular lesions (group 11b). The comparison between the two groups was done as regarded the clinical and laboratory tests of the patients (Tables 2 and 3).

The mean and standard deviation of JADAS of all patients was 4.05 \pm 1.47 . The mean of JADAS in patients with and without ocular lesion

\begin{tabular}{|l|c|c|c|c|}
\hline \multirow{2}{*}{ Demographic data } & \multicolumn{2}{|c|}{ Group II (n=52) } & \multicolumn{2}{c|}{ Group I (n= 20) } \\
\cline { 2 - 5 } & Range & Mean \pm SD & Range & Mean \pm SD \\
\hline Age (years) & 6 to 19 y & $10.2 \pm 3.2$ & $5-16$ & $9.80 \pm 6.46$ \\
\hline Age at onset (years) & $4-13$ & $6.9 \pm 2.2$ & & \\
\hline Duration of disease (Months) & 6 to 116 & $38.5 \pm 32.8$ & \\
\hline Sex \% & No (58) & frequency & No (20) & frequency \\
\hline Male: & 12 & $20.7 \%$ & 3 & $15 \%$ \\
\hline Female: & 46 & $79.3 \%$ & 17 & $85 \%$ \\
\hline \multicolumn{4}{|c|}{ Table 1: Demographic data of JIA patientsand control. } \\
\hline
\end{tabular}

\begin{tabular}{|l|c|c|c|c|c|}
\hline \multirow{2}{*}{ Clinical feature } & \multicolumn{2}{|c|}{$\begin{array}{c}\text { Group 11a } \\
\text { (N=16) }\end{array}$} & \multicolumn{2}{|c|}{$\begin{array}{c}\text { Group 11b } \\
\text { (N=42) }\end{array}$} & P \\
\cline { 2 - 5 } & NO & frequency & No & frequency & \\
\hline Arthritis & 14 & $87.5 \%$ & 17 & $40.4 \%$ & $0.001^{\text {** }}$ \\
\hline Arthralgia & 14 & $87.5 \%$ & 31 & $73.8 \%$ & $0.01^{*}$ \\
\hline Oral ulcer & 2 & $12.5 \%$ & 8 & $19 \%$ & 0.43 \\
\hline Fever & 4 & $25 \%$ & 6 & $14.3 \%$ & 0.27 \\
\hline Lymphadenopathy & 0 & - & 5 & $11.9 \%$ & 0.18 \\
\hline Hepatomegally & 4 & $25 \%$ & 5 & $11.9 \%$ & 0.20 \\
\hline splenomegally & 2 & $12.5 \%$ & 4 & $9.5 \%$ & 0.53 \\
\hline Rash & 2 & 12.5 & 2 & $4.7 \%$ & 0.30 \\
\hline Pericarditis & 0 & - & 2 & $4.7 \%$ & 0.52 \\
\hline Pleutitis & 0 & - & 3 & $7.1 \%$ & 0.37 \\
\hline
\end{tabular}

Table 2: Comparison between JIA patients as regard of clinical features. 
Citation: EL-Shereef RR, lofty G, Mohamed AS, Hamdy L (2014) Ocular Manifestation of Juvenile Idiopathic Arthritis and its Relation to Disease Activity. J Arthritis 3: 137. doi:10.4172/2167-7921.1000137

Page 3 of 6

\begin{tabular}{|l|c|c|c|c|c|}
\hline \multirow{2}{*}{ Clinical feature } & \multicolumn{2}{|c|}{$\begin{array}{c}\text { Group 11a } \\
\text { (N=16) }\end{array}$} & \multicolumn{2}{|c|}{$\begin{array}{c}\text { Group 11b } \\
\text { (N=42) }\end{array}$} & P \\
\cline { 2 - 5 } & NO & frequency & NO & frequency & \\
\hline $\begin{array}{l}\text { Antinuclear } \\
\text { antibody }\end{array}$ & 12 & $5.2 \%$ & 14 & 33.3 & $0.005^{\text {** }}$ \\
\hline Rheumatoid factor & 2 & $3.4 \%$ & 8 & 19 & 0.43 \\
\hline $\begin{array}{l}\text { Erythrocyte } \\
\text { sedimentation rate }\end{array}$ & 6 & $10.3 \%$ & 25 & 59.5 & $0.001^{\text {** }}$ \\
\hline C reactive protein & 2 & $3.4 \%$ & 25 & 59.5 & $0.001^{\text {** }}$ \\
\hline Leucocytosis & 2 & $3.4 \%$ & 7 & 16.7 & 0.52 \\
\hline Thrombocytosis & 4 & $6.9 \%$ & 6 & 14.3 & 0.27 \\
\hline Anemia & 6 & $10.3 \%$ & 0 & 0 & 0.01 \\
\hline
\end{tabular}

Table 3: Comparison between JIA patients as regard of laboratory features.

\section{ocular symptoms in JIA patients}

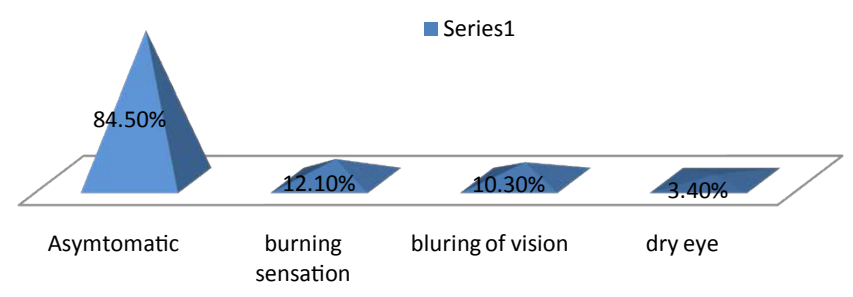

Figure 1: Reported the ocular symptoms in JIA patients.

\begin{tabular}{|c|c|c|c|c|c|}
\hline \multirow[t]{2}{*}{ Ocular abnormalities } & \multicolumn{2}{|c|}{ Patients $(\mathrm{N}=58)$} & \multicolumn{2}{|c|}{ Control $(\mathrm{N}=20)$} & \multirow[t]{2}{*}{$\mathbf{P}$} \\
\hline & NO & frequency & NO & frequency & \\
\hline Unilateral keratoconjunctivitis Sicca & 3 & $5.2 \%$ & 0 & 0 & $0.0001^{* * *}$ \\
\hline Bilateral keratoconjunctivitis Sicca & 2 & $3.4 \%$ & 0 & 0 & $0.0001^{* * *}$ \\
\hline Unilateral visual field defect (VFD) & 6 & $10.3 \%$ & 0 & 0 & $0.0001^{* * *}$ \\
\hline Bilateral visual field defect & 2 & $3.4 \%$ & 0 & 0 & $0.0001^{* * *}$ \\
\hline Increase intraocular pressure. & 2 & $3.4 \%$ & 0 & 0 & $0.0001^{* * *}$ \\
\hline Unilateral uveitis & 4 & $6.9 \%$ & 0 & 0 & $0.0001^{* * *}$ \\
\hline Bilateral uveitis & 6 & $10.3 \%$ & 0 & 0 & $0.0001^{* * *}$ \\
\hline Cataract. & 2 & $3.4 \%$ & 0 & 0 & $0.0001^{* * *}$ \\
\hline Macular edema & 4 & $6.8 \%$ & 0 & 0 & $0.0001^{* * *}$ \\
\hline
\end{tabular}

Table 4: Prevalence of ocular lesions in patients and controls.

was $3.81 \pm 1.5 \& 4.14 \pm 1.5$ respectively. The mean of JADAS in patients with and without uveitis was $3.46 \pm 1.5$ and $4.17 \pm 1.4$ respectively. There was no statistically significant difference between these groups of patients as regarded the disease activity index $(\mathrm{P}<0.4,0.1)$. In our JIA patients, 15 patients had minimal active disease, 6 in remission under medication and 37 patients had active JIA

\section{Patients with ocular lesions}

The frequency of patients with ocular lesion in patients with JIA was $27.6 \%$. Most of JIA were asymptomatic, 49 (84.48\%) for ocular manifestation. Nine patients (15.5\%) complained of ocular manifestations in the form of blurring of vision, burning sensation and dryness. The highest prevalence of them was burning sensation (7 patients), the least prevalence was eye dryness (2 patents) (Figure 1). Six patients only exhibited significant eye lesion. There was no significant relation between the presence of symptoms and presence of ocular lesion $(\mathrm{p}<0.1)$. Patients with ocular abnormalities were significantly had an early disease onset and longer disease duration than those without any lesions $(\mathrm{p}<0.001)$. There was a highly statistically significant difference between patients and controls as regarding all ocular lesions, which was significantly higher in the patients group (Table 4, Figure 2). The number of patients with ocular lesions was 16 patients, presented as single lesion or multiple. For example in one patient of our study, there is uveitis, glaucoma and macular edema; another had VFD, uveitis and cataract.

\section{Ocular involvement}

The most common ocular manifestation of JIA is uveitis (17.2\%), it is presented in $4(6.9 \%)$ patients unilaterally and $6(10.3 \%)$ patients bilaterally (Figure 2). The characteristics of JIA patients with and without uveitis were compared in (Table 5). Uveitis occurred in our study between 9 and 13 yrs of age, with a mean of 11.4 yrs (S.D. 1.7). Patients with uveitis were significantly younger at onset of arthritis, more in females and ANA-positive than the JIA patients without uveitis. By multivariate analysis, predictors of uveitis included age at onset $(\mathrm{P}<0.003$, OR 0.95, CI 0.90-0.96), disease duration $(\mathrm{P}<0.0001$, OR 1.10; CI 1.07-1.15) and ANA-positivity ( $<<0.002$; OR 2.63, CI 1.733.78) besides the presence of a certain JIA subgroup (oligoarthritis) that appeared to be at a particularly high risk of uveitis $(\mathrm{P}<0.002)$, while, gender $(\mathrm{P}<0.66)$, and ESR $(\mathrm{P}<0.08)$ had no significant influence.

\section{Corneal}

The corneal manifestations of JIA are usually confined to the epithelium. KCS (8.5\%), it is reported in $3(5.2 \%)$ patients unilaterally and $2(3.4 \%)$ patients bilaterally (Figure 2 ) in the form of abnormal Schirmer test and rose Bengal tests.

\section{Others ocular lesions}

The visual field defect (VFD) present in $13.7 \%$, bilateral VFD present

\section{ocular lesion in JIA}

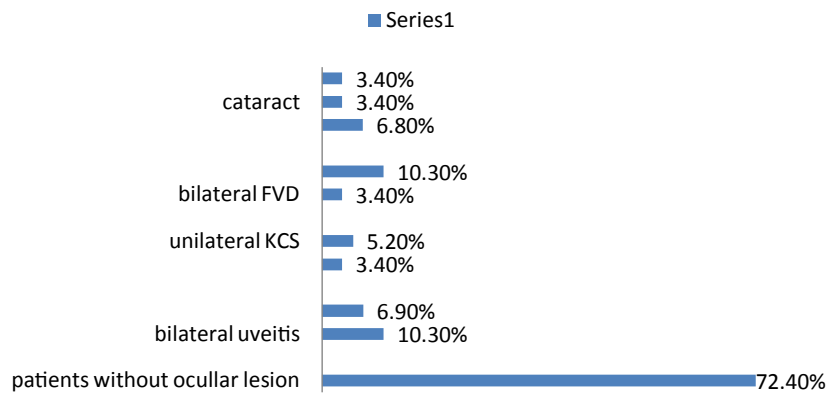

Figure 2: Frequency of ocular lesions in JIA patients.

\begin{tabular}{|c|c|c|c|c|c|}
\hline \multirow[t]{2}{*}{ CHARACTERISTIC } & \multicolumn{2}{|c|}{$\begin{array}{l}\text { Patients with } \\
\text { uveitis }(N=10)\end{array}$} & \multicolumn{2}{|c|}{$\begin{array}{l}\text { Patients without } \\
\text { uveitis }(\mathrm{N}=48)\end{array}$} & \multirow[t]{2}{*}{$\mathbf{P}$} \\
\hline & NO & frequency & NO & frequency & \\
\hline JIA subgroups (n/\%) & & & & & $0.002^{* *}$ \\
\hline -Polyarthritis (RF+). & - & - & 8 & $16.7 \%$ & \\
\hline -Polyarthritis (RF-) & 1 & $10 \%$ & 18 & $37.5 \%$ & \\
\hline -Oligoarthritis (persistent) & 7 & $70 \%$ & 7 & $14.6 \%$ & \\
\hline -Oligoarthritis (extended) & 2 & $20 \%$ & 4 & $8.3 \%$ & \\
\hline -Systemic arthritis & - & - & 11 & $22.9 \%$ & \\
\hline Female \% & 8 & $80 \%$ & 38 & $79.2 \%$ & 0.66 \\
\hline ANA positive (\%) & 9 & $90 \%$ & 17 & $35.4 \%$ & $0.002^{* *}$ \\
\hline Arthritis & 9 & $90 \%$ & 22 & $68.7 \%$ & $0.01^{*}$ \\
\hline Age at onset in years mean (SD) & $5.1 \pm 0.7$ & & $7.3 \pm 2.2$ & & $0.003^{* *}$ \\
\hline $\begin{array}{l}\text { Disease duration in year mean } \\
\text { (SD) }\end{array}$ & $6.4 \pm 1.9$ & & $2.5 \pm 2.3$ & & $0.000^{\star * *}$ \\
\hline
\end{tabular}

Table 5: Comparison between patients with and without uveitis in JIA. 
in $6(10.3 \%)$ and unilateral VFD in $2(3.4 \%)$ in the form of reduced sensitivity, peripheral field defects, and enlargement of the blind spot related to the optic nerve affection. Four patients had macular oedema (6.8\%), each of increase intraocular pressure and cataract found in 2 patients (3.4\%). These lesions presented as single or combined lesions.

The mean and standard deviation of disease duration of all patients was $38.5 \pm 32.8$. The mean of disease duration in patients with and without ocular lesion was $70.5 \pm 20.9$ and $26.4 \pm 28.1$ respectively. The mean of disease duration in patients with and without uveitis was $76.8 \pm 23.4$ and $30.6 \pm 28.7$ respectively (Figures 3 and 4 ). There is highly statistically significant correlation between presence of ocular lesion and disease duration especially uveitis disease (Figure 5). In JIA patient groups, there was no correlation between activity of JIA disease and presence of ocular lesion especially uveitis $(\mathrm{r}<0.54)$.

\section{Discussion}

In our study, the ocular manifestations was presented in about $(27.6 \%)$ of the patients with JIA which was nearly the same result was noticed by others [13,14]. The ocular involvement was more common in JIA and the most common manifestations were burning sensation and the disease mostly asymptomatic. Uveitis is the most

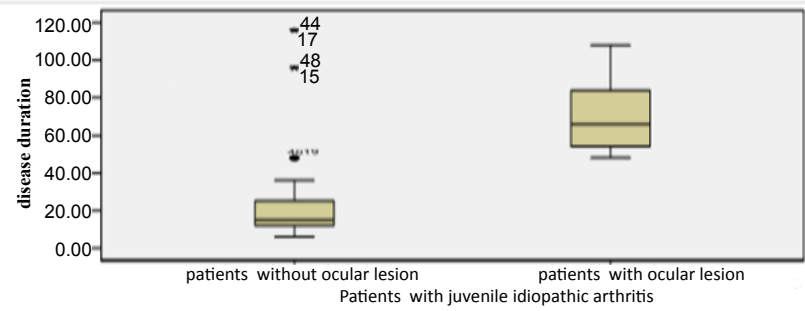

Figure 3: Showed comparison of disease duration in patient's subgroups.

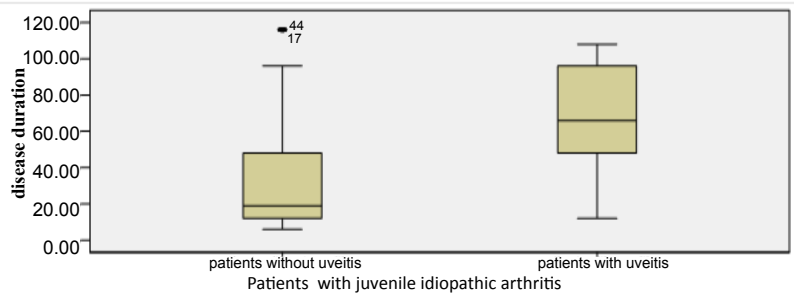

Figure 4: Showed comparison of disease duration in patients with and without uveitis.

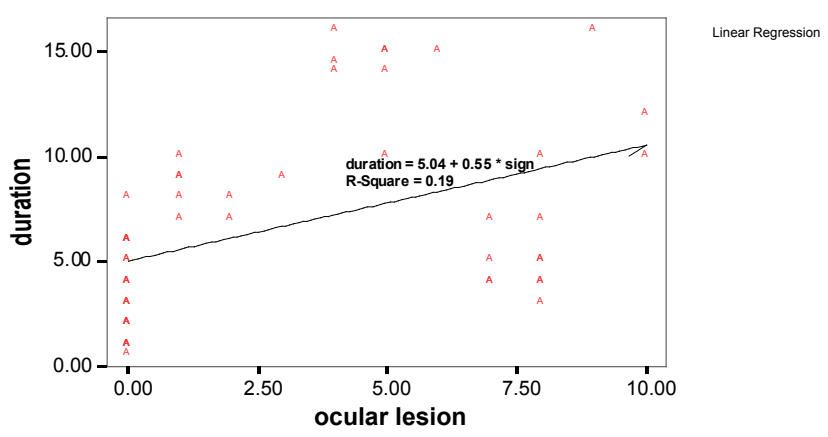

Figure 5: Showed the correlation between the ocular lesion and the disease duration. common ocular manifestation, and the visual morbidity is usually due to uveitis. This is in agreement with other studies who reported that the prevalence of eye disease in children with JIA is from $2 \%$ to $34 \%$ [3] and eye disease associated with JIA often has no symptoms, although blurred vision may be an early sign. This study reported that, prevention of eye problems from progressing to the point that vision loss occurs by regular eye examinations.

In our study, most of eye disease developed in pauciarticular JIA with positive antinuclear antibody (ANA) test. This is in agreement with another study that showed that the eye disease develops in about $20 \%$ of children with pauciarticular JIA (oligoarthritis), particularly children who have a positive ANA test result [14].

In the present study, external ocular manifestations in the form of dry eye was manifested in about $8.5 \%$ of our patients, nearly the same findings present with those studies, which reported from India, $12 \%$ of 50 JIA children had KCS [15] Their patient cohort was different from the one in the present study, as most of the patients were male, their cut-off value in the Schirmer test was $\leq 10 \mathrm{~mm}$ in five minutes, but similar to our study, it had polyarthritis and systemic-onset arthritis. Children with corticosteroid treatment or topical treatment for uveitis were excluded. Nearly the same findings presented with another study from Turkey described the occurrence of KCS in 64 JIA patients and controls [16]. Dry eye were found in $10.9 \%, 1.5 \%$ of the patients and controls respectively.

Our result differ from previous study [17], who showed the prevalence of dry eye was higher than our result $17 \%$, Their patient cohort was different from the one in the present study, they included all the 192 consecutive JIA patients born in 1990-1995 who visited both a pediatric rheumatologist and an ophthalmologist during the study period and who thus formed a cross-sectional age group. In their study, the mean duration of arthritis was six years, and the majority of the patients had ongoing medical treatment for arthritis. Chronic asymptomatic anterior uveitis was also a frequent feature of the disease in the study group (31\%). Patients with JIA complain of aches or discomfort in their joints less often than adults. Perhaps that is the reason why they seldom spontaneously report any symptoms of dry eyes if not particularly asked about them [17].

The lack of association between signs and symptoms of dry eyes in JIA children has earlier been reported by Nichols and colleagues [18]. This was in agreement of our study and other previous study $[3,17]$.

In our study uveitis was the most common presentation of ocular lesion of JIA, represent $17.2 \%$, it is presented in 4 (6.9\%) patients unilaterally and $6(10.3 \%)$ patients bilaterally.

Similar results, the intraocular inflammation primarily affects the iris and ciliary body (iridocyclitis), but the choroid may also be involved. Overall, the frequency varies from $2 \%$ to $34 \%$ in children with JIA $[6,17,19]$. The confusingly different prevalence rates can be attributed to the different study designs used. The previous studies were based on different classification criteria for childhood chronic arthritis, e.g. the American College of Rheumatology (ACR) or the European League Against Rheumatism (EULAR) criteria. There are still no large investigations available using the currently applied International League of Associations for Rheumatology (ILAR) criteria. The few population-based data are of limited value due to the small numbers of patients included. The studies from tertiary uveitis and rheumatology centres were profoundly different owing to selection criteria and follow-up. 
The present study discloses that, the risk of uveitis differs enormously between the various JIA subgroups. The vast majority of uveitis patients in our study had oligoarthritis. This data was in agreement with previous observations $[12,19,20]$. Our data support the high frequency of ANA in oligoarthritis associated uveitis that was also noted previously [19,21-23]. Similar to previous reports, uveitis occurred predominantly in JIA with early onset of disease in our study $[19,21]$. In our study, mean arthritis onset was $5.1 \pm 0.7$ in JIA with uveitis, and $7.3 \pm 2.2$ in JIA without uveitis. Herein, mean arthritis onset was $7.0 \mathrm{yrs}$ (median 7.0. range 0-15) in JIA patients without uveitis and 3.8 yrs (median 3.0, range 0 -15) in patients who had uveitis. The mean age of uveitis manifestation in JIA patients was $7 \mathrm{yrs}$ in previous studies [24] and 5.2yrs (median 4, range 0-16) in previous study [19]. However, the observations herein illustrate that uveitis may occur at any age. In only $2.7-6.8 \%$ of the JIA patients, the uveitis manifests itself before arthritis $[21,24,25]$, in previous study in $10 \%$ of the children. It has been previously shown that in 25 to $33 \%$ of the patients, uveitis was detected synchronously with the onset of arthritis [19,21]. In $\sim 50 \%$, it appeared within the first 3 months after arthritis $[6,23]$, and in $90 \%$ within the first 4 yrs [23], but may occasionally develop up to $10 \mathrm{yrs}$ after arthritis [26]. In our study, all patients with uveitis were discovered after onset of arthritis.

In the present study, another ocular lesion present in the form of cataract, glaucoma, and macular edema which were not common in JIA patient and were associated with uveitis, so may be complication of uveitis. The typical complications published previously included cataract (19-81\%), glaucoma (8-38\%), band keratopathy (7-70\%), posterior synechiae $(8-75 \%)$ and ocular hypotony $(19 \%)[19,23,27,28]$. As macular edema was frequently noted in the previous and also the present study $[19,25]$, beside slit-lamp examination, funduscopy should always be considered.

\section{Conclusion}

Ocular manifestations of JIA are common and can be sightthreatening. Almost any part of the eye and visual pathway can be affected by inflammatory processes. Uveitis is the most common ocular manifestation, and the visual morbidity is usually due to its complication. Dry eye symptoms and signs are common in JIA. Ophthalmological screening should be initiated early which allow earlier diagnosis of uveitis. This can improve the visual prognosis of uveitis, owing to earlier and intensive treatment.

\section{Recommendation}

Unlike the joints, ocular involvement with juvenile rheumatoid arthritis is most often asymptomatic; yet, the inflammation can cause serious morbidity with loss of vision. We strongly advice for a strict ocular follow-up in patients with JIA and for accurate eye checks early in life because this may be used as a preventive tool for ocular diseases associated to autoimmune disorders. Scheduled slit-lamp examinations by an ophthalmologist at specific intervals can detect ocular disease early, and prompt treatment can prevent vision loss. Because early detection and treatment of inflammatory eye disease gives a child the best chance of a good outcome.

\section{Acknowledgement}

This work was supported by a rheumatology, ophthalmology, and pediatric department in El-Minia university hospital. Many thanks for all.

\section{References}

1. Juvenile Idiopathic Arthritis (JIA): Joint Disorders: Merck Manual For health care Professional". Retrieved 2008-12-15.
2. William C ShielJr (2012) "Juvenile Rheumatoid Arthritis:" Medicine Net p. 1. "Arthritis affects approximately one child in every 1,000 in a given year. Fortunately, most of these cases are mild. However, approximately one child in every 10,000 will have more severe arthritis that doesn't just go away."

3. Cassidy J, Kivlin J, Lindsley C, Nocton J; Section on Rheumatology; Section on Ophthalmology (2006) Ophthalmologic examinations in children with juvenile rheumatoid arthritis. Pediatrics 117: 1843-1845.

4. Kotaniemi K, Kautiainen H, Karma A, Aho K (2001) Occurrence of uveitis in recently diagnosed juvenile chronic arthritis: a prospective study. Ophthalmology 108: 2071-2075.

5. Boone MI, Moore TL, Cruz OA (1998) Screening for uveitis in juvenile rheumatoid arthritis. J PediatrOphthalmol Strabismus 35: 41-43.

6. Majumder PD, Biswas J (2013) Pediatric uveitis: An update. Oman J Ophthalmol 6: 140-150.

7. Rosenberg AM (2002) Uveitis associated with childhood rheumatic diseases. CurrOpinRheumatol 14: 542-547.

8. Keenan JD, Tessler HH, Goldstein DA (2008) Granulomatous inflammation in juvenile idiopathic arthritis-associated uveitis. J AAPOS 12: 546-550.

9. Petty RE, Southwood TR, Baum J, Bhettay E, Glass DN, et al. (1998) Revision of the proposed classification criteria for juvenile idiopathic arthritis: Durban, 1997. J Rheumatol 25: 1991-1994.

10. Bloch-Michel E, Nussenblatt RB (1987) International Uveitis Study Group recommendations for the evaluation of intraocular inflammatory disease. Am J Ophthalmol 103: 234-235.

11. Consolaro A, Ruperto N, Bazso A, Pistorio A, et al. (2009) Development and validation of a composite disease activity score for juvenile idiopathic arthritis," Arthritis Rheum 61: 658-666.

12. Magni-Manzoni S, Ruperto N, Pistorio A Sala E, Solari N, Cugno PE, et al. "Development and validation of a preliminary definition of minimal disease activity in patients with juvenile idiopathic arthritis," Arthritis Rheum

13. Wallace CA, Ravelli A, Huang B, Giannini EH "Preliminary validation of clinical remission criteria using the OMERACT filter for select categories of juvenile idiopathic arthritis," J Rheumatol 33:789-95

14. Wallace CA, Sherry DD (2003) Juvenile rheumatoid arthritis. In CD Rudolph et al., eds., Rudolph's Pediatrics, McGraw-Hill, New York

15. Akinci A, Cakar N, Uncu N, Kara N, Acaroglu G (2007) Keratoconjunctivitissicca in juvenile rheumatoid arthritis. Cornea 26: 941-944.

16. Mody GM, Hill JC, Meyers OL (1988) Keratoconjunctivitissicca in rheumatoid arthritis. ClinRheumatol 7: 237-241.

17. Kotaniemi KM, Salomaa PM, Sihto-Kauppi K, Säilä HM, Kauppi MJ (2009) An evaluation of dry eye symptoms and signs in a cohort of children with juvenile idiopathic arthritis. ClinOphthalmol 3: 271-275.

18. Nichols KK, Nichols JJ, Mitchell GL (2004) The lack of association between signs and symptoms in patients with dry eye disease. Cornea 23: 762-770.

19. Heiligenhaus A, Niewerth M, Ganser G, Heinz C, Minden K, and German Uveitis in Childhood Study Group; Prevalence and complications of uveitis in juvenile idiopathic arthritis in a population-based nation-wide study in Germany: suggested modification of the current screening guidelines. Rheumatology 2007; 1 of 5

20. Kanski JJ, Shun-Shin GA (1984) Systemic uveitis syndromes in childhood: an analysis of 340 cases. Ophthalmology 91: 1247-1252.

21. Kanski JJ (1977) Anterior uveitis in juvenile rheumatoid arthritis. Arch Ophthalmol 95: 1794-1797.

22. Petty RE, Smith JR, Rosenbaum JT (2003) Arthritis and uveitis in children. A pediatric rheumatology perspective. Am J Ophthalmol 135: 879-884.

23. Kotaniemi K, Kautiainen H, Karma A, Aho K (2001) Occurrence of uveitis in recently diagnosed juvenile chronic arthritis: a prospective study. Ophthalmology 108: 2071-2075.

24. Wolf MD, Lichter PR, Ragsdale CG (1987) Prognostic factors in the uveitis of juvenile rheumatoid arthritis. Ophthalmology 94: 1242-1248. 
Citation: EL-Shereef RR, lofty G, Mohamed AS, Hamdy L (2014) Ocular Manifestation of Juvenile Idiopathic Arthritis and its Relation to Disease Activity. J Arthritis 3: 137. doi:10.4172/2167-7921.1000137

Page 6 of 6

25. Dana MR, Merayo-Lloves J, Schaumberg DA, Foster CS (1997) Visual outcomes prognosticators in juvenile rheumatoid arthritis-associated uveitis. Ophthalmology 104: 236-244

26. Cassidy JT, Sullivan DB, Petty RE (1977) Clinical patterns of chronic iridocyclitis in children with juvenile rheumatoid arthritis. Arthritis Rheum 20: 224-227.
27. Rosenberg KD, Feuer WJ, Davis JL (2004) Ocular complications of pediatric uveitis. Ophthalmology 111: 2299-2306.

28. Sijssens KM, Rothova A, Berendschot TT, de Boer JH (2006) Ocula hypertension and secondary glaucoma in children with uveitis. Ophthalmology 113: 853-859. 